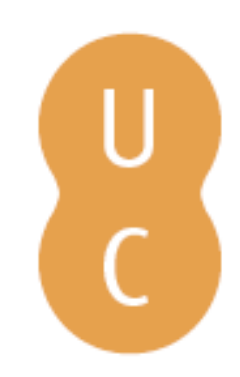

\title{
nombalina
}

\section{Projectos pin (potencial interesse nacional): um instrumento para promover 0 crescimento económico à custa da sustentabilidade ambiental?}

\author{
Autor(es): $\quad$ Nunes, Flávio; Jesus, Cecília \\ Publicado por: Imprensa da Universidade de Coimbra \\ URL \\ persistente: URI:http://hdl.handle.net/10316.2/30758 \\ DOI: $\quad$ DOI:http://dx.doi.org/10.14195/978-989-26-0244-8_7 \\ Accessed : $\quad$ 26-Apr-2023 05:56:35
}

A navegação consulta e descarregamento dos títulos inseridos nas Bibliotecas Digitais UC Digitalis, UC Pombalina e UC Impactum, pressupõem a aceitação plena e sem reservas dos Termos e Condições de Uso destas Bibliotecas Digitais, disponíveis em https://digitalis.uc.pt/pt-pt/termos.

Conforme exposto nos referidos Termos e Condições de Uso, o descarregamento de títulos de acesso restrito requer uma licença válida de autorização devendo o utilizador aceder ao(s) documento(s) a partir de um endereço de IP da instituição detentora da supramencionada licença.

Ao utilizador é apenas permitido o descarregamento para uso pessoal, pelo que o emprego do(s) título(s) descarregado(s) para outro fim, designadamente comercial, carece de autorização do respetivo autor ou editor da obra.

Na medida em que todas as obras da UC Digitalis se encontram protegidas pelo Código do Direito de Autor e Direitos Conexos e demais legislação aplicável, toda a cópia, parcial ou total, deste documento, nos casos em que é legalmente admitida, deverá conter ou fazer-se acompanhar por este aviso.

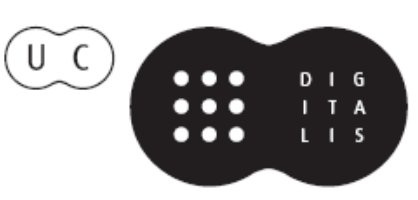




\section{TRUNFOS DE UMA}

\section{EOGRAFIA ACIVA}

\section{DESENVOLVIMENTO LOCAL,}

AMBIENTE,

ORDENAMENTO

E TECNOLOGIA

Norberto Santos

Lúcio Cunha

COORDENAÇÃO 
Flávio Nunes ${ }^{1}$, Cecília Jesus ${ }^{2}$

${ }^{1}$ Universidade do Minho | CEGOT - Centro de Estudos em Geografia e Ordenamento do Território

${ }^{2}$ Universidade do Minho | Mestranda em Planeamento e Gestão do Território

\author{
PROJECTOS PIN (POTENCIAL INTERESSE NACIONAL): \\ UM INSTRUMENTO PARA PROMOVER O CRESCIMENTO ECONÓMICO \\ À CUSTA DA SUSTENTABILIDADE AMBIENTAL?
}

\title{
1. INTRODUÇÃO
}

O planeamento regional e urbano tem sido confrontado com o difícil desafio de saber integrar as duas vertentes do binómio 'rigidez-flexibilidade' no processo de gestão dos planos (Bothe, 2009; Brandão, 2009). Se, por um lado, se considera muito avançado o esquema normativo vigente de produção de regras que garantem a necessária rigidez nos modos de uso, ocupação e transformação do solo, por outro lado, consideram-se menos desenvolvidos os mecanismos de flexibilidade que permitem integrar as oportunidades imprevisíveis à data da produção e aprovação dos instrumentos de gestáo territorial. Com a experiência adquirida na prática do processo de planeamento vai-se tomando cada vez mais consciência de que as incertezas (anteriormente ignoradas) são intrínsecas à evoluçáo da sociedade e das dinâmicas territoriais (não são de forma alguma elimináveis). Assim sendo, a prática do planeamento territorial deve conseguir integrá-las e desenvolver disposiçóes para que possa lidar continuamente com elas, tirando partido do seu aparecimento quando tal for conveniente, por via da adopção de mecanismos que permitam integrar níveis desejados de flexibilidade e de adaptabilidade na gestão dos planos existentes.

A evoluçáo do planeamento no sentido de uma maior flexibilidade é defendida (Portas, 2003) de modo a evitar a reprovação de pretensóes de investimento que, embora possam ser iniciativas chave para a sustentabilidade, coesão e competitividade dos territórios, não são consideradas formalmente compatíveis com as categorias de uso do solo previstas aquando da aprovação dos planos.

Face a este contexto este estudo tem como objectivo avaliar, a partir da realidade portuguesa, os resultados e efeitos práticos da concepção e aplicação de um desses mecanismos que visam testar a introdução de margens de flexibilidade na gestão dos planos de ordenamento do território. O mecanismo em questáo consiste nos Projectos de Potencial Interesse Nacional (projectos PIN), introduzidos em 2005, que visam facilitar a captação e agilizar a aprovaçáo de avultados investimentos empresariais privados, considerados de grande relevância para o progresso e crescimento económico do país, quer pelos empregos criados quer pelos montantes de financiamento envolvidos. 
Existe, contudo, uma percepção generalizada ${ }^{1}$ de que a conotação de projecto PIN constitui, sobretudo, uma forma de contornar condicionantes legais em matéria de ordenamento do território e de preservação de valores ambientais (nomeadamente com a emissão de autorizaçóes especiais para a instalação destes investimentos em áreas de salvaguarda, como a Rede Natura 2000, ou a Reserva Ecológica ou Agrícola Nacional).

Este estudo procura questionar estes eventuais efeitos perversos com base numa metodologia que envolveu a criação de uma base de dados, a partir da recolha e sistematização de informação referente à totalidade das candidaturas submetidas e já aprovadas como projectos PIN (um total de 88 projectos), com base na qual se procedeu a uma análise estatística e cartográfica. $\mathrm{O}$ tratamento dessa informação, recolhida junto da Comissão para a Avaliação e Acompanhamento dos Projectos PIN, permitiu caracterizar todos esses investimentos, não só em termos da sua repartição espacial e sectores de actividade envolvidos, mas também ao nível dos volumes de investimento associados e das suas repercussóes na criação de emprego. Por outro lado, analisaram-se também as áreas de implantação territorial desses investimentos com o propósito de confrontá-las com as directrizes expressas nas respectivas Plantas de Condicionantes do uso do solo, procurando questionar até que ponto este mecanismo promove o crescimento económico do país à custa da submissão e degradação dos valores territoriais e ambientais.

\section{PROJECTOS PIN: DEFINIÇÃO E REQUISITOS}

Com a intenção de dinamizar a economia e gerar mais e melhor investimento, o Governo de Portugal decidiu, em 2005, criar novos mecanismos de acompanhamento e desenvolvimento processual de projectos que sejam reconhecidos como sendo de Potencial Interesse Nacional (PIN). Os Projectos PIN são iniciativas empresariais privadas caracterizadas pelo elevado valor de investimento envolvido (o qual, de acordo com o DL no 174/2008, terá de ser superior a 25 milhóes de euros) e que revelam um potencial em termos do desenvolvimento nacional e/ou regional.

$\mathrm{Na}$ sua definição, o estatuto PIN não confere direitos especiais aos promotores destas iniciativas, pelo contrário, estabelece um conjunto de objectivos e requisitos, aos quais terão de dar cumprimento, sobretudo a nível do respeito pela componente ambiental e territorial. A principal diferença em relaçáo a outro tipo de projectos de investimento é o seu acompanhamento permanente pela Comissão de Avaliação e Acompanhamento dos PIN (CAA-PIN) ${ }^{2}$, o que lhes permite ultrapassar barreiras burocráticas e tornar mais célere o processo de aprovação e execução dos mesmos.

O Decreto - Lei no 174/2008 de 26 de Agosto, estabelece o conjunto de requisitos a que estes projectos se encontram sujeitos, nomeadamente: investimento global superior a 25 milhóes de euros; adequada sustentabilidade ambiental e territorial; carácter inovador ou colaboração com entidades do sistema científico e tecnológico; criação mínima de 100

\footnotetext{
${ }^{1}$ A comunicação social, diversas organizações ambientais, entidades e partidos políticos revelam o carácter promíscuo deste tipo de projectos, os quais, alegadamente, buscam uma forma de contornar os instrumentos rígidos do planeamento territorial, atribuindo principal enfoque à vertente económica em detrimento da territorial e ambiental.

${ }^{2}$ Constituída por seis entidades: Agência de Investimento e Comércio Externo de Portugal; Instituto de Conservação da Natureza; Agencia Portuguesa de Ambiente; Turismo de Portugal; Direcção Geral de Pequenas e Médias Empresas e Direcção Geral de Ordenamento do Território e Desenvolvimento Urbano.
} 
postos de trabalho directos; prevalência para áreas de I\&D; contribuição para a economia de regióes menos desenvolvidas; eficiência energética ou favorecimento de fontes de energia renováveis; dinamização do investimento empresarial associado a actividades que diversifiquem a base económica existente; criação de emprego qualificado e implementação de características de inovação na estrutura empresarial local.

Trata-se, portanto, de projectos de investimentos que, na sua concepção, apresentam um evidente potencial de desenvolvimento regional, quer pelo contributo que se pretende que tragam à criação e qualificação do emprego, quer pelo incentivo à modernização e inovação da base produtiva. Pode inclusivamente referir-se que existe a preocupaçáo de actuarem para um melhor ordenamento do território ${ }^{3}$, na medida em que devem respeitar a sustentabilidade ambiental e territorial do local onde se inserem e actuarem enquanto factores de desenvolvimento das regióes mais periféricas e desfavorecidas.

\section{A REPARTIÇÃO ESPACIAL DOS PROJECTOS PIN E O CONTRIBUTO NA CRIAÇÃO DE EMPREGO}

Considerando os dados de Outubro de 2009, recolhidos junto da CAA-PIN, existiam à data 88 projectos PIN aprovados, a que corresponde um investimento total de 35,6 bilióes de Euros e um contributo, em termos de emprego directo previsto, de cerca de 83 mil novos postos de trabalho. Contudo, destes 88 projectos apenas $40 \%$ se encontram em fase de execução, ou seja, projectos que, beneficiando do estatuto PIN, já ultrapassaram (de uma forma mais célere) a fase burocrática de acompanhamento processual e de licenciamento pelas diferentes entidades competentes. Os 35 projectos em execuçáo correspondem a um investimento de 7,5 bilióes de Euros e 17,6 mil postos de trabalho.

Ao nível da repartição espacial destes investimentos (Figura 1) verifica-se uma maior concentraçáo destes projectos no sul do país, sobretudo no Algarve e no Alentejo (essencialmente no litoral e na área envolvente à barragem do Alqueva). Os concelhos com maior concentração deste tipo de investimentos (Évora, Grândola, Sines e Estarreja) não integram as duas áreas metropolitanas, o que indicia o seu potencial para o desenvolvimento das regióes menos desenvolvidas, sobretudo no Centro e Sul do país, dado que na região Norte existe a prevalência destes projectos nos concelhos mais urbanizados do litoral.

Relativamente ao volume de investimento por projecto PIN (Figura 2), e embora a lei estabeleça o valor mínimo de 25 milhóes de euros, importa referir que as pretensóes de investimento são muito superiores a esse limar uma vez que o valor médio de investimento por projecto é de cerca de 405 milhóes de Euros. Tratam-se portanto de iniciativas empresariais de grande dimensáo (localizando-se em concelhos do Alentejo alguns dos maiores volumes de investimento) pelo que se assumem de facto como importantes factores de desenvolvimento regional, sobretudo no que diz respeito ao incentivo que promovem para a modernização e diversificação da base económica em concelhos distantes das grandes formaçóes urbano-metropolitanas. Pelo contrário, no que concerne ao seu contributo na

\footnotetext{
${ }^{3}$ Segundo a Carta Europeia do Ordenamento do Território os seus objectivos fundamentais devem visar a preocupaçáo de promover o desenvolvimento sócio-económico equilibrado das regióes; a melhoria da qualidade de vida e do bem-estar individual; a gestão responsável dos recursos naturais e a protecção do ambiente, e a utilização racional do território (CE, 1984).
} 
Figura 1 - Repartição espacial dos projectos PIN, por concelho.

PIN's ( $n^{\circ}$ de projectos)
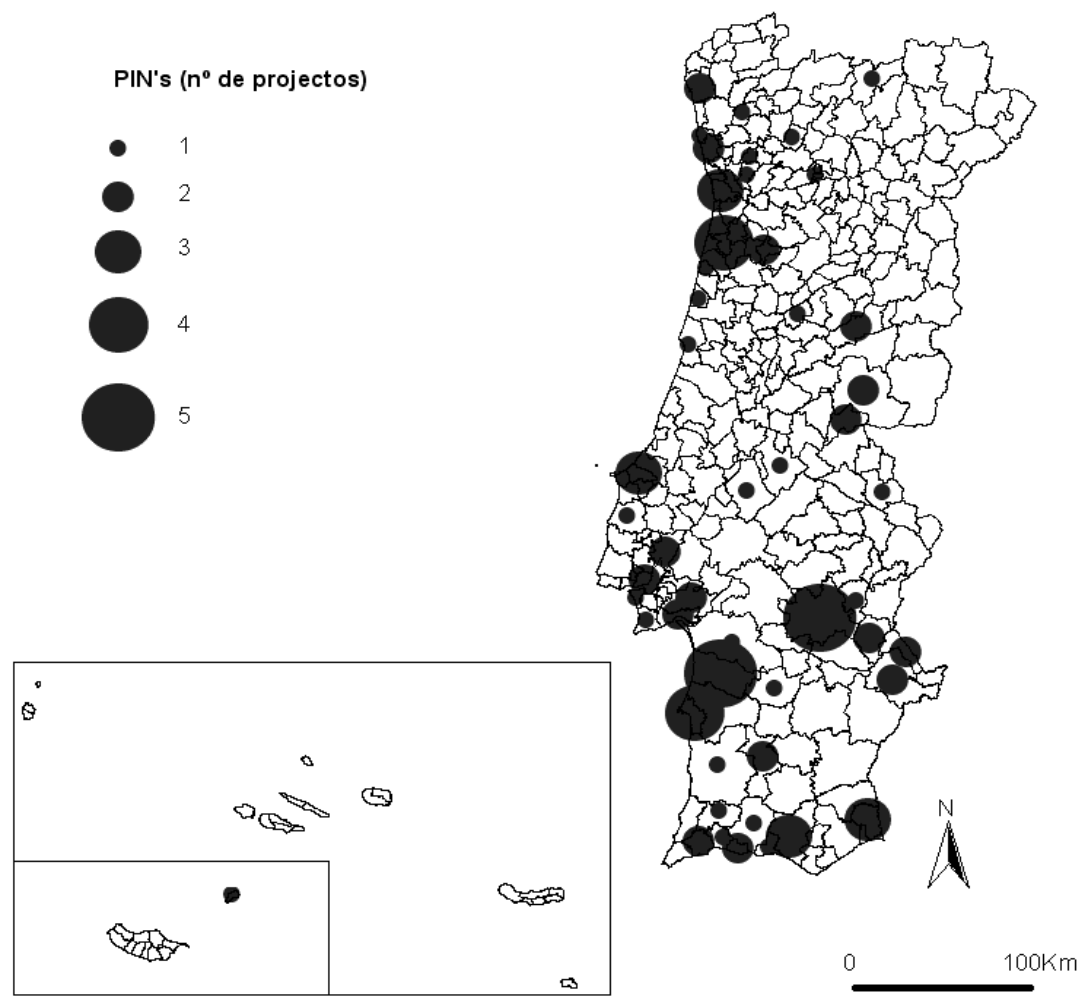

Fonte: dados referentes a 30 de Outubro de 2009, obtidos em http://www.portugalglobal.pt

Figura 2 - Projectos PIN por escalóes de investimento.

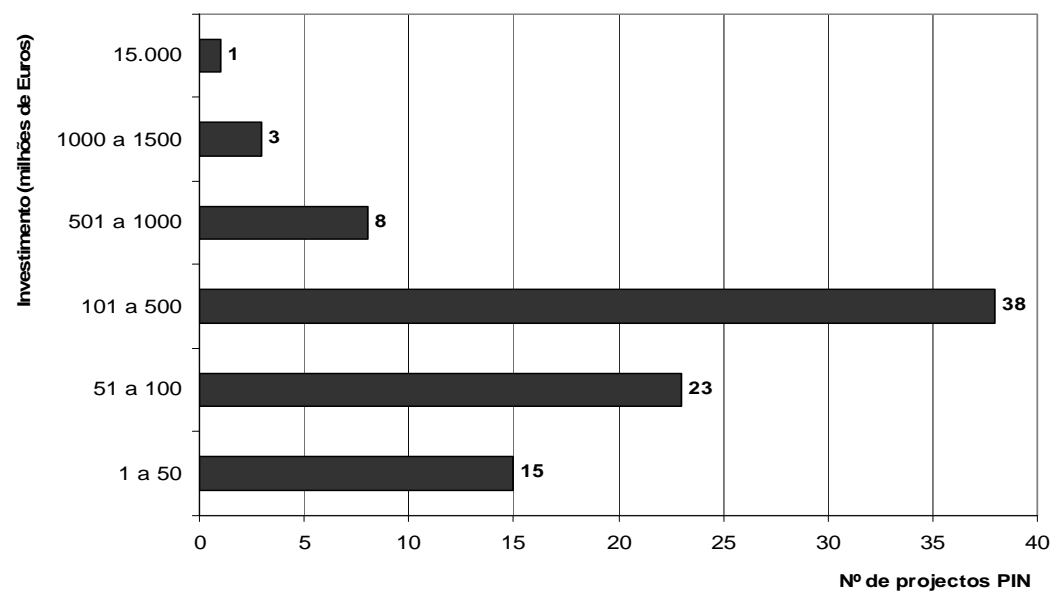

Fonte: dados referentes a 30 de Outubro de 2009, obtidos em http://www.portugalglobal.pt 
Figura 3. Repartição espacial do investimento e emprego associado aos Projectos PIN Total de Investimento em PIN's por concelho (milhões de Euros)
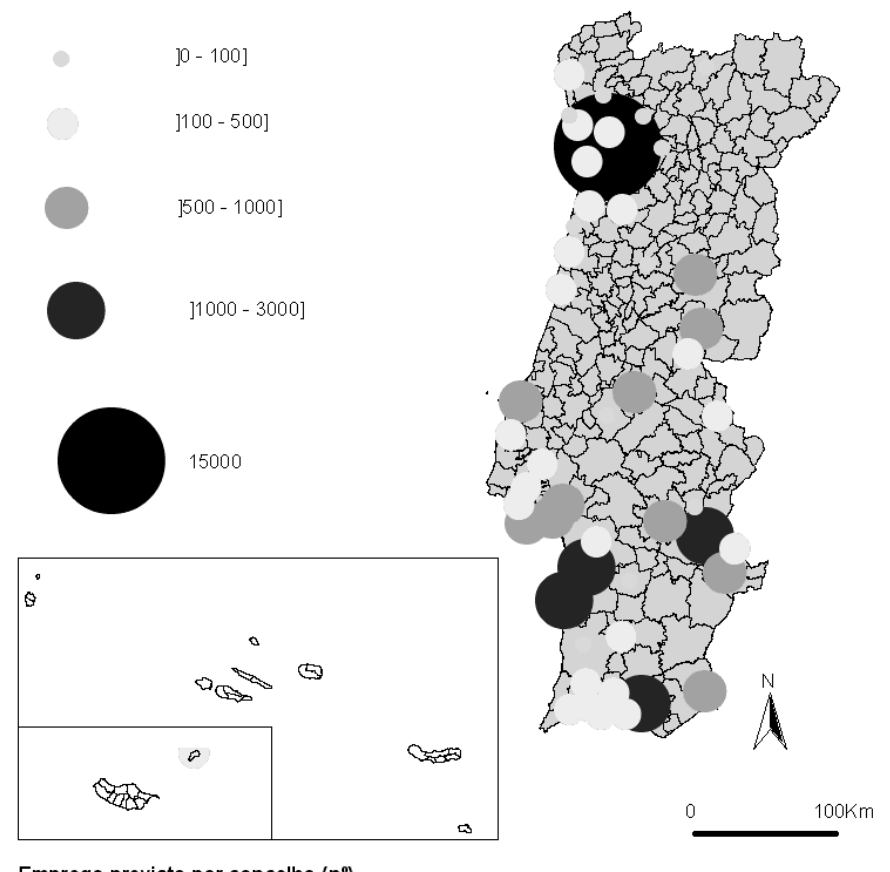

Emprego previsto por concelho $\left(n^{\circ}\right)$

]0 - 500]

$500-1000]$

]1000 - 5000]
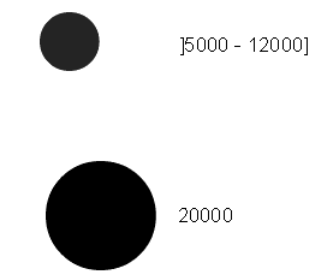

20000
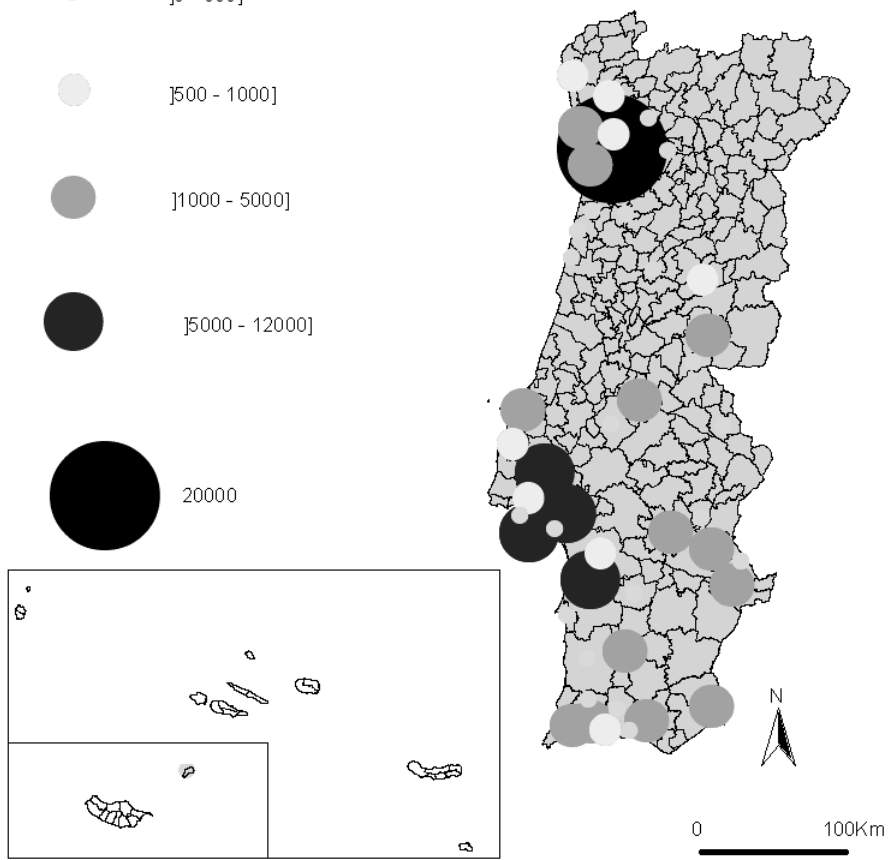

Fonte: dados referentes a 30 de Outubro de 2009, obtidos em http://www.portugalglobal.pt 
criação de emprego, e na sua qualificação, as repercussões são menos evidentes e decisivas em termos do esbatimento de assimetrias geográficas de desenvolvimento (Figura 3). Vejase que alguns dos concelhos que mais beneficiarão ao nível do emprego directo previsto associado a estes projectos estão enquadrados na Área Metropolitana de Lisboa, ou na proximidade da Área Metropolitana do Porto ${ }^{4}$.

Um outro dado que comprova o facto de se tratar de projectos de maior dimensão no investimento que lhes está associado do que no emprego directo que prevêem criar, é o facto de visarem sobretudo o aparecimento de micro, pequenas e médias empresas (até 250 trabalhadores) e não de grandes empresas, contrariamente ao que é muitas vezes divulgado (Figura 4). Este facto é compreensível dado se procurar com estes projectos de investimento a criação de empresas que procurem ser competitivas em sectores de maior valor acrescentado, de elevada incorporação de conhecimento, inovação e de grande intensidade tecnológica e, por isso, mais exigentes ao nível da qualificação e especialização da mão-de-obra. Deste modo, ao se pretender que estes investimentos contribuam para o desejado aparecimento de um novo modelo de desenvolvimento económico no país, náo se pode, portanto, esperar que correspondam sobretudo a empresas de mão-de-obra intensiva.

Figura 4. Projectos PIN segundo a dimensão da empresa a criar (postos de trabalho).

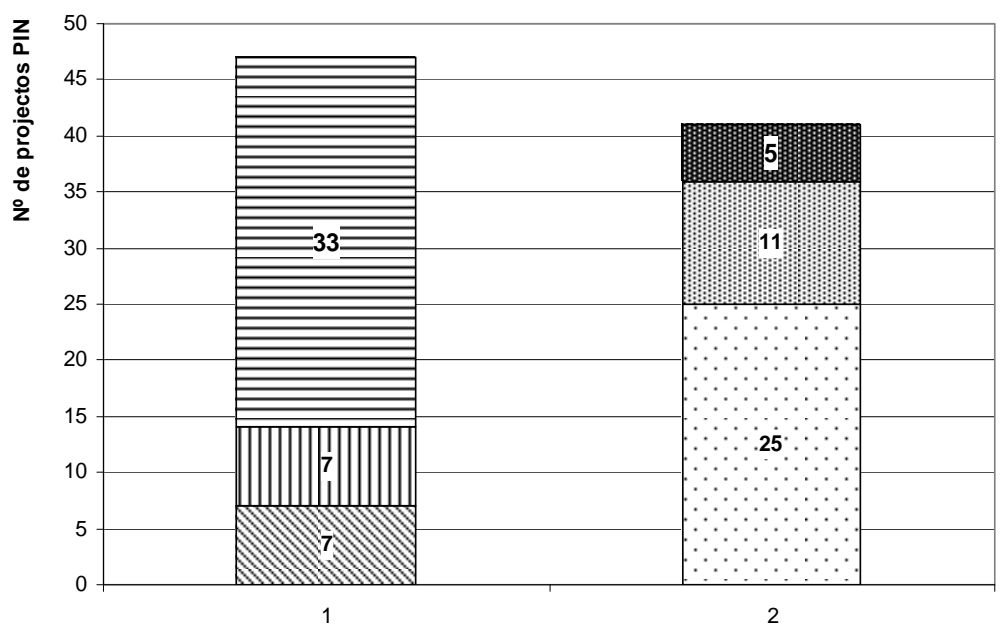

Médias empresas (50 a 249 trabalhadores)

Pequenas empresas (10 a 49 trabalhadores)

Micro empresas (até 9 trabalhadores)
眭 Grandes empresas (mais de 5000 trabalhadores)

Grandes empresas (1000 a 4999 trabalhadores)

Grandes empresas (250 a 999 trabalhadores)

Fonte: dados referentes a 30 de Outubro de 2009, obtidos em http://www.portugalglobal.pt

\footnotetext{
${ }^{4}$ Para Paredes está em fase de acompanhamento a candidatura de um projecto de negócio (Planit Valley), que pretende promover o aparecimento de uma cidade tecnológica em 17 quilómetros quadrados no domínio das tecnologias da informação, representando um investimento de 15 biliōes de euros e a prevista criação de 20 mil postos de trabalho, sendo até à data o projecto de maior dimensão em avaliação pela CAA-PIN.
} 


\section{ProjeCtOS PIN: SECTORES DE ACTIVIDADE PRIVILEGIADOS}

A maioria dos projectos PIN (51\%) corresponde a investimentos na área do turismo (hotéis, resorts, campos de golf, ...), seguindo-se os investimentos nas indústrias transformadoras $(28 \%)$ e as iniciativas empresariais no sector energético (11\%), preferencialmente direccionadas para a exploração das energias renováveis (Tabela 1). Todavia, verifica-se que embora dominantes e de maior dimensão em termos de investimento e emprego previsto, os projectos na área do turismo sáo os que apresentam maior complexidade de aprovaçáo, uma vez que apenas cerca de $1 / 4$ desses projectos estáo já licenciados e em execução. Importa também salientar que as candidaturas de projectos para indústrias transformadoras e para a produção energética são responsáveis apenas por $9 \%$ do emprego total previsto, o que demonstra o contributo dos PIN's sobretudo para a terciarização da economia portuguesa.

Tabela 1. Projectos PIN segundo o sector de actividade

\begin{tabular}{|c|c|c|c|c|c|c|}
\hline $\begin{array}{c}\text { Sector de } \\
\text { actividade }\end{array}$ & $\begin{array}{c}\text { No de } \\
\text { Projectos } \\
\text { PIN }\end{array}$ & $\begin{array}{c}\text { Projectos } \\
\text { PIN em } \\
\text { execuçáo }\end{array}$ & $\begin{array}{c}\text { Investi- } \\
\text { mento }\end{array}$ & $\begin{array}{c}\text { Emprego } \\
\text { directo } \\
\text { previsto }\end{array}$ & $\begin{array}{c}\text { Investimento } \\
\text { médio por } \\
\text { projecto }\end{array}$ & $\begin{array}{c}\text { Emprego } \\
\text { médio por } \\
\text { projecto }\end{array}$ \\
\hline do total) & $\begin{array}{c}\text { (\% do } \\
\text { sector })\end{array}$ & $\begin{array}{c}\text { (\% do } \\
\text { total })\end{array}$ & $\begin{array}{c}\text { (\% do } \\
\text { total })\end{array}$ & $\begin{array}{c}\text { (milhóes de } \\
\text { Euros) }\end{array}$ & $\begin{array}{c}\text { (postos de } \\
\text { fogos) }\end{array}$ \\
\hline Turismo & $45(51 \%)$ & $24 \%$ & $33 \%$ & $48 \%$ & 263 & 883 \\
\hline Endústria & $25(28 \%)$ & $60 \%$ & $17 \%$ & $7 \%$ & 241 & 234 \\
\hline Outros & $8(9 \%)$ & $50 \%$ & $45 \%$ & $43 \%$ & 2016 & 4428 \\
\hline Total & $\begin{array}{c}\mathbf{8 8} \\
(100 \%)\end{array}$ & $40 \%$ & $100 \%$ & $100 \%$ & 405 & 943 \\
\hline
\end{tabular}

Fonte: dados referentes a 30 de Outubro de 2009, obtidos em http://www.portugalglobal.pt

Nota: O projecto PIN do concelho de Paredes, pela sua dimensão (ver nota de rodapé 4), é responsável pelo peso dos 'outros' sectores de actividade em termos de investimento e emprego.

Os projectos turísticos localizam-se essencialmente no Sul do país (Figura 5), contudo náo apenas no Algarve mas procurando também explorar os atractivos turísticos presentes noutros concelhos, nomeadamente no Alentejo litoral e na imediação da albufeira do Alqueva, o que sugere um contributo importante destes projectos para combater a sazonalidade que ainda tende a caracterizar o turismo português. Tratam-se por isso de investimentos relevantes ao nível da diversificaçáo da base económica, não só ao estimularem a actividade turística no Alentejo mas também ao contribuírem para o aparecimento de outras actividades no Norte Litoral, essencialmente industrial, e para onde se prevê investimentos relevantes na exploração de energias renováveis e na criação de serviços qualificados. A reduzida terciarização do tecido empresarial do Norte Litoral é um problema reconhecido (Pires e Nunes, 2009) e para cuja resolução os projectos PIN parecem contribuir. 
Figura 5. Repartição espacial dos projectos PIN, por sectores de actividade.

Sectores de actividade dos PIN's, por concelho
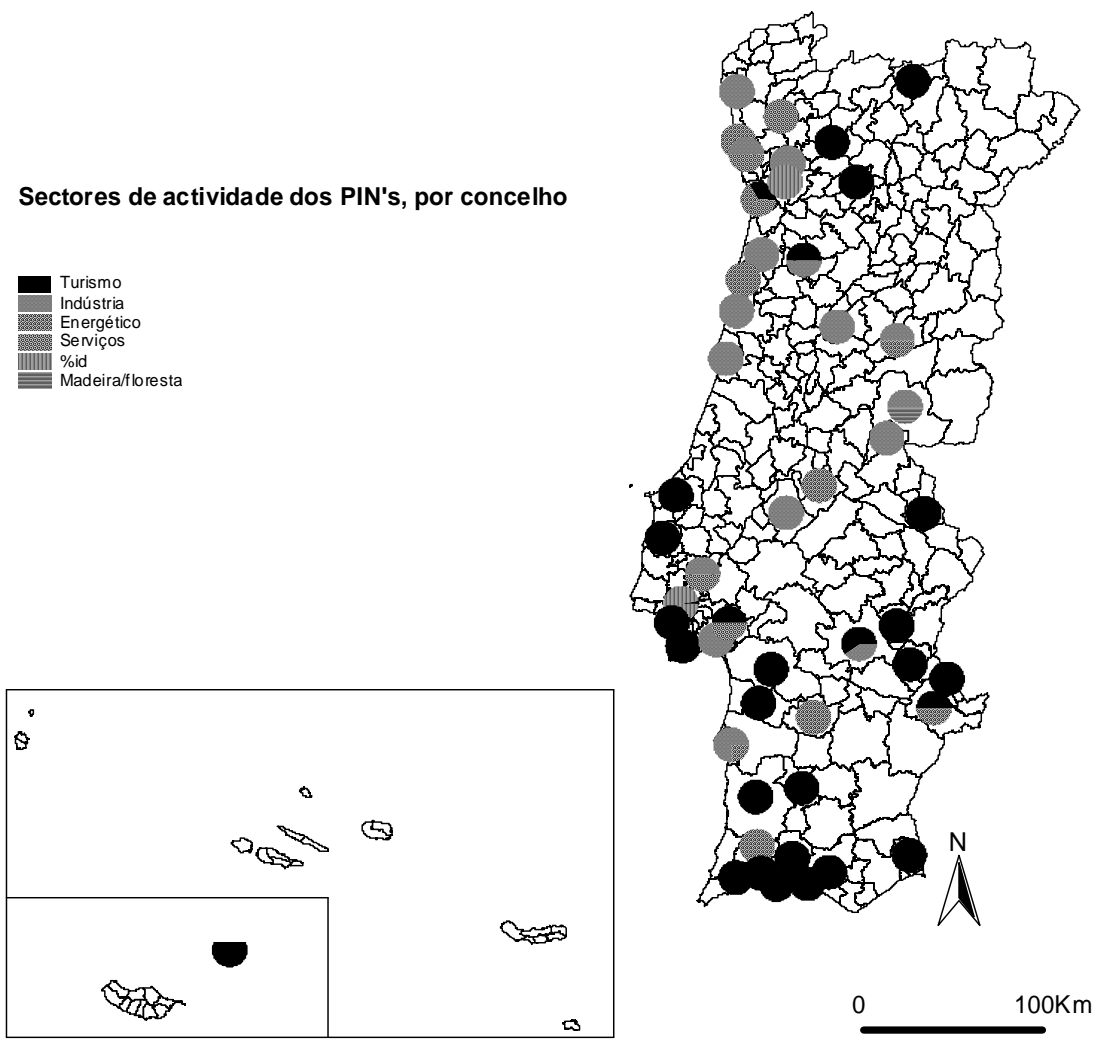

Fonte: dados referentes a 30 de Outubro de 2009, obtidos em http://www.portugalglobal.pt

\section{CONCLUSÃO}

Como conclusão procura-se avaliar sumariamente o risco de utilização do estatuto PIN para promover o desenvolvimento económico do país à custa da introdução de efeitos nefastos em termos de sustentabilidade ambiental. A este respeito importa começar por referir que mais de metade (51\%) do total de candidaturas apresentadas a projectos PIN foram reprovadas pela CAA-PIN, o que desde logo indicia uma ponderaçáo criteriosa na utilização dos benefícios inerentes a este mecanismo de agilização processual com vista à aprovação de investimentos empresariais.

Importa também destacar que os PIN previstos para implantação em áreas com relevantes condicionantes ao uso do solo (REN, RAN, Rede Natura) correspondem a menos de $2 / 5$ do total dos projectos (38\%). Sendo que os PIN's mais conflituosos com a sustentabilidade ambiental e territorial são sobretudo do sector do turismo (mais de $70 \%$ do investimento e do emprego previsto no sector do turismo corresponde a projectos cuja localização interfere com condicionantes ao uso do solo), razáo pela qual a proporção destes projectos já licenciados e em fase de execuçáo é bastante inferior à que se regista noutros sectores de actividade. 
Embora a maioria das candidaturas não coincida com investimentos que coloquem em risco a sustentabilidade ambiental é certo que existem 33 projectos onde esse risco parece existir, sendo que esse risco é maior no Sul do país, onde se concentra a maioria dos PIN's que conflituam com condicionantes ao uso do solo. Todavia, a magnitude desse risco apenas poderá ser avaliada com uma análise mais cuidada feita a partir da realização de estudos de caso (metodologia em que se baseará o desenvolvimento das próximas etapas desta investigação), com os quais se procurará perceber o modo como foi possível aprovar estes investimentos em áreas com restriçóes legalmente instituídas. Ou seja, em que circunstância foi possível contornar a rigidez do planeamento viabilizando pretensóes de uso do solo contrárias às disposiçóes inscritas nos planos.

Apesar de não ser ainda possível responder a essa questão pode contudo constatar-se que a utilização do estatuto PIN, como mecanismo de flexibilização na aplicação dos instrumentos de gestão do território, não garante o princípio da igualdade perante a globalidade dos agentes utilizadores do território. O recurso a este mecanismo está limitado apenas a grandes grupos económicos (agentes com intenção de investimento superior a 25 milhóes de euros), o que pode introduzir uma injustiça em termos de gestão territorial, cujo risco deve ser convenientemente equacionado. Até porque, numa perspectiva de desenvolvimento local podem surgir pretensóes de ocupação do solo que, embora não apresentem esta magnitude de investimento, podem revelar um enorme potencial na modernização e qualificação do tecido produtivo, quer pelo efeito catalizador que incorporam quer pela diversificação da base económica que propiciam.

\section{REFERÊNCIAS BIBLIOGRÁFICAS}

Bothe, A. 2009, 'A flexibilização e a privatização no planeamento urbanístico alemão', in F. Gonçalves; J. Bento, J. e Z. Pinheiro (coord.). Os dez anos da Lei de Bases da Política de Ordenamento do Território e de Urbanismo, AD URBEM, Lisboa, pp. 121-134

Brandão, A. L. 2009, 'Pensar a cidade, no tempo da incerteza. Sobre modelos e paradigmas da cidade contemporânea., On the Waterfront, Vol. 12, pp. 22-36.

CE 1984, A Carta Europeia do Ordenamento do Território, Comissão Europeia, Bruxelas.

Portas, N., 2003, 'El surgimiento del proyecto urbano', Perspectivas urbanas. Estudios sobre urbanismo y procesos urbanos, N. 03, pp. 15-26.

Pires, I. \& Nunes, F. 2009, 'Dinâmicas territoriais de evolução do emprego em Portugal (1985-2005)', Revista Sociedade e Trabalho, No. 37, pp. 95-109.

\section{FONTES ELECTRÓNICAS}

CAA-PIN: Comissão de Avaliação e Acompanhamento dos Projectos PIN http://www.portugalglobal.pt (consultado a 30-10-2009). 